\title{
DURABILITY CRITERIA FOR RUBBER PARTS OF MACHINES
}

\author{
Svetlana Polukoshko ${ }^{1}$, Vladimirs Gonca ${ }^{2}$ \\ ${ }^{1}$ Ventspils University of Applied Sciences, Latvia; ${ }^{2}$ Riga Technical University, Latvia \\ pol.svet_a@inbox.lv, vladimirs.gonca@rtu.lv
}

\begin{abstract}
Natural and synthetic rubber (elastomeric materials) are used for fabrication of vibration dampers, shock absorbers, seismic isolation, bearing seals, compensation devices. These elements are applied both in machine manufacturing and in civil engineering. Elastomers absorb input energy much better than other construction materials and this fact gives them many engineering advantages. The disadvantages of elastomeric materials are ageing, accumulation of damage, i.e. changing the mechanical properties over time and lowering their operational capability. The durability of rubber elements under cyclic loading is determined according to various criteria: thermodynamic process of damage, energy damage criterion, entropic damage criterion, engineering damage criterion, dissipative damage criterion. Experiments show that the nature of the destruction process is unidirectional and irreversible. Deformation is accompanied by dissipative heating, which is also facilitated by low thermal conductivity of rubber. To calculate the durability of rubber parts, a large amount of experimental data is required, which is currently insufficient. In this paper, the dissipative damage criterion is considered, which allows determining the limiting number of loading cycles at a given operating temperature and damage parameter. The destruction occurs when the concentration of broken molecular bonds reaches a certain critical level, the numerical value of which is constant of the material. This value is called the damage parameter, which is a constant value for a given material, empirically determined. In addition, it is necessary to know the dynamic shear modulus of the material and the relative deformation of the element. Such approach allows to correctly appoint the grade of rubber for anti-vibration devices at the design stage.
\end{abstract}

Keywords: rubber, cyclic loading, heating, ageing, damage parameter, durability.

\section{Introduction}

Natural and synthetic rubber is widely used in machine manufacturing, shipbuilding, civil engineering for fabrication of different parts, such as compensating devices, vibration dampers, shock absorbers, bearings, joint hinges etc. [1;2].

Rubbers, as elastomeric materials, are hereditary-elastic media, i.e. such media, which are characterized by the presence of a significant part of the viscous component, memory of previous actions, instability of physical and mechanical properties over time (aging effects), dependence on the loading mode, influence of the external environment, presence of large dissipation, temperature of dissipative heating, etc. Such features of the mechanics of deformation and fracture of hereditary-elastic media determine the choice of their fracture criteria [2-5].

Since rubber parts of machines usually work under impulsive load, alternating-sign load, periodical and non-periodical high-frequency load, usual fracture criteria (first of all, permissible stresses $(\sigma)$ and permissible deformations $(\varepsilon)$ ) turned out to be acceptable for particular cases and mainly under static loading. With long-term cyclic loads, they actually turned out to be unusable. In this paper we consider calculation of hereditary-elastic media using the durability criteria. To determine the durability of rubber elements during their cyclic loading, it is necessary to have experimental information. Durability is determined by various criteria: thermodynamic process of destruction, energy criterion of destruction, entropy criterion of destruction, criterion of destruction by damage, engineering criterions of destruction, dissipative fracture criterion [6-10].

The carried out experimental studies of the phenomenon of destruction of materials made it possible to establish a number of its general laws. First of all, attention is drawn to the unidirectional and irreversible nature of the destruction process, according to which it should be characterized not only by the current values of the defining parameters, but also by the entire previous history of these parameters changes. The initial defects in the material, structural failure are distributed over the volume of the body in a random way, determining the statistical character of the phenomenon. The dispersion of the experimental data when testing "identical" samples confirms the statistical nature of fracture. Experimental information on the process of destruction of various materials indicates the existence of two stages in it.

At the first stage, called local destruction, there is accumulation of all kinds of structural disturbance, defects in the material. This stage ends when a macroscopic crack is formed in the body by 
fusion of a part of micro-damages. The second stage of destruction, called global destruction or macrodestruction, consists in propagation of the formed macrocrack and ends with breaking of the body into parts [7].

The destruction of rubbers also has a number of specific laws inherent only to these materials. First of all, it is significant dissipative heating accompanying the deformation of the samples. The temperature in the samples can reach critical values, at which intense thermal destruction of the material occurs $[9 ; 11]$.

To a certain extent, the low thermal conductivity of rubbers also contributes to significant heating of the samples. As a result, the need to take into account the thermal effects in the destruction of rubbers is obvious [10-12].

The listed features of the phenomenon of destruction of rubbers require an integrated approach for its satisfactory description. However, this approach has not yet been developed. The approach based on the synthesis of the thermodynamics of irreversible processes and the continuous media mechanics is also quite conform to a satisfactory description of this phenomenon and an understanding of its essence. Taking into account that the first and second laws of thermodynamics lead to a number of general relations, it may be concluded that the process of destruction must obey them [7].

The simplest and at the same time quite reliable method for determining the rubber service life at alternating stress is estimation of the self-heating temperature, that is, each certain self-heating temperature corresponds to a certain service life. For some brands of elastomers such dependencies have been experimentally established and tabulated [10]. Such experiments take a long time.

In research works of recent years, mainly experimental methods for determining the durability of cutting of new samples of standard shape are presented, the results of which are difficult to use, since the shape of the part and the methods of its fastening sharply affect the operation of rubber [11-14]. Therefore, testing of specific work pieces is also necessary.

A lot of works pay attention to calculation of the durability of rubber elements by the finite element method using computer programs. The difficulty lies in creating a material model, so when using programs, such as ANSYS, CATTIA, Endurca, the error is from 20\%. to $40 \%[15 ; 16]$.

In this paper calculation of the fatigue life based on experiments for some types of rubbers and calculation of the fatigue life based on the dissipative criterion are considered, the theoretical background of the calculation and the results of experiments are shown.

\section{Materials and methods}

\subsection{Fatique lifetime calculation based on experimental data}

For the fatigue durability of natural and synthetic rubbers estimation of their testing has been carried out at the Scientific Research Institute VNIIMASHRAN in Moscow during many years [10]. Based on numerous experiments on the effect of cyclic loads on rubber vibration isolators, the following dependence was established for a number of cycles $\mathrm{N} *$ until destruction:

$$
N^{*}=N(W, T)=\left(\frac{W_{p}}{W}\right)^{n},
$$

where $W_{p}$ - specific work of destruction of the material, $\mathrm{MNm} \cdot \mathrm{m}^{-3}$;

$W$ - specific potential energy, $\mathrm{MNm} \cdot \mathrm{m}^{-3}$

$n$ - design coefficient.

The specific work of destruction of the material is determined as

$$
W_{p}=W_{1} e^{-W_{2} T},
$$

where $W_{1}$ and $W_{2}$-tabular data, presented below in Table 1 [10];

$T$ - operating temperature, ${ }^{\circ} \mathrm{C}$. 
Table of design parameters

\begin{tabular}{|c|c|c|c|c|c|c|c|}
\hline Rubber brand & $\mathbf{8 1 5 7}$ & $\mathbf{8 1 6 4}$ & $\mathbf{8 4 7 0}$ & $\mathbf{8 5 0 8}$ & $\mathbf{8 8 7 1}$ & $\mathbf{1 0 4 2 9}$ & $\mathbf{1 0 0 8}$ \\
\hline$W_{1}, \mathrm{MNm} \cdot \mathrm{m}^{-3}$ & 33.2 & 34.3 & 46.1 & 37.7 & 46.4 & 58.9 & 92.8 \\
\hline$W_{2}, \mathrm{deg}^{-1}$ & 0.0128 & 0.0128 & 0.0180 & 0.0227 & 0.0261 & 0.0260 & 0.0890 \\
\hline$n$ & 2.890. & 3.22 & 2.76 & 3.41 & 2.94 & 3.64 & 3.62 \\
\hline
\end{tabular}

\subsection{Dissipative damage criterion for lifetime evaluation}

Within the framework of the thermodynamic approach to describing the destruction of rubber, it is possible to create a different criterion of destruction. As a complete set of thermodynamic parameters we choose $\{\varepsilon ; T ; p(t)\}$, where $\varepsilon_{i j}$ is the strain tensor, $i, j=1,2,3 ; p(t)$ is the function of material damage. In thermodynamics of continuous media, the functions of the internal energy $U$ and entropy $S$ are used. Besides them, it is convenient to introduce more functions of the state of the system: the function of density of the free energy $f$ and the function of internal dissipation $[1 ; 7]$ :

$$
f=U-T S,
$$

and the internal dissipation function $D$ defined by the expression:

$$
D=\sigma_{i j} \dot{\varepsilon}_{i j}-\dot{f}-S \dot{T} .
$$

Using the local form of the first law of thermodynamics for the case under consideration, we have:

$$
\dot{U}=\sigma_{i j} \dot{\varepsilon}_{i j}+r-\operatorname{div} \vec{q},
$$

where $\quad r$-power of internal heat sources $\mathrm{J} \cdot \mathrm{s}^{-1}$;

$\vec{q}-$ vector of the heat flux, $\mathrm{J}$.

The relation representing the equation of conservation of energy in terms of entropy and internal dissipation may be obtained taking into account (3) and (4):

$$
T \dot{S}=D+r-\operatorname{div} \vec{q} .
$$

On the other hand, since $S=S\left(\varepsilon_{i j}, T, p\right)$ it may be written:

$$
\dot{S}=\frac{\partial S}{\partial \varepsilon_{i j}} \dot{\varepsilon}_{i j}+\frac{\partial S}{\partial T} \dot{T}+\frac{\partial S}{\partial p} \dot{p} .
$$

Combining it with (6), we come to equality:

$$
\frac{1}{T}(D+r-\operatorname{div} \vec{q})=\frac{\partial S}{\partial \varepsilon_{i j}} \dot{\varepsilon}_{i j}+\frac{\partial S}{\partial T} \dot{T}+\frac{\partial S}{\partial p} \dot{p},
$$

in which we set the following approximations:

$$
\frac{\partial S}{\partial p}=\alpha_{1}, \frac{\partial S}{\partial \varepsilon_{i j}}=\beta_{i j}^{1},
$$

where $\alpha_{1}$ and $\beta_{i j}^{1}$-established constants.

Let us consider the case of an isothermal destruction process, which is common in practice. In this case, the amount of heat produced by internal sources is completely dissipated into the environment, and the body temperature remains stationary. The equation (8) for the isothermal process may be simplified and written in the form:

$$
\frac{1}{T} D=\alpha_{1} \dot{p}+\beta_{i j}^{1} \dot{\varepsilon}_{i j} .
$$

Averaging it over the deformation cycle, we get: 


$$
\alpha_{1}\langle\dot{p}\rangle=\frac{1}{T}\langle D\rangle,
$$

where

$$
\begin{aligned}
\langle\dot{p}\rangle=\frac{\omega}{2 \pi} \int_{t}^{t+2 \pi / \omega} \dot{p} d t,\langle D\rangle & =\frac{\omega}{2 \pi} \int_{t}^{t+2 \pi / \omega} D d t,\left\langle\dot{\varepsilon}_{i j}\right\rangle=\frac{\omega}{2 \pi} \int_{t}^{t+2 \pi / \omega} \varepsilon_{i j} d t, \\
\left\langle\varepsilon_{i j}\right\rangle & =\frac{\omega}{2 \pi} \int_{t}^{t+2 \pi / \omega} \varepsilon_{i j} d t=0,
\end{aligned}
$$

if the rubber element deformed by the law

$$
\varepsilon_{i j}=\varepsilon_{i j}^{0} \sin \omega t .
$$

The equation (11) is a kinetic equation for the damage parameter, which may be used to construct the damage criterion. We assume that destruction of the system occurs, when the concentration of broken molecular bonds of rubber reaches a certain critical level $\Delta p_{k r}$, the numerical value of which is constant of the material:

$$
p\left(t^{*}\right)-p(0)=\int_{0}^{t^{*}}\langle\dot{p}\rangle d t=\Delta p_{k r}=\text { const } .
$$

Substituting the expression (12) into (13), we obtain the destruction condition:

$$
\Delta p_{k r}=\int_{0}^{t^{*}} \frac{1}{\alpha_{1} T}\langle D\rangle d t .
$$

Based on definition (4), the internal dissipation function may be concretized as follows:

$$
D=\frac{1}{\gamma_{1}} \sigma_{i j} \dot{\varepsilon}_{i j},
$$

where $\gamma_{1=\text { const. }}$

Taking into account (15), the destruction condition (14) will be written as:

$$
\Delta p_{k r}=\int_{0}^{t} \frac{1}{\alpha_{1} T}\left(\frac{\omega^{t+2 \pi / \omega}}{2 \pi} \int_{t}^{\frac{1}{\gamma_{1}}} \sigma_{i j} \dot{\varepsilon}_{i j} d t\right) d t .
$$

After integration we finally get

$$
\Delta p_{k r}=\frac{1}{k_{1} T} \frac{G_{0} \varepsilon_{0}^{2} \psi}{2} N^{*},
$$

where $k_{1}=\alpha_{1} \gamma_{1}$.

Here the new empirical constant $k_{1}$ is introduced, which is a characteristic of rubber as a material and does not depend on the type of the element structure and on the type of deformation.

Hence, the limiting number of cycles to destruction is equal:

$$
N^{*}=\frac{2 k_{1} T \Delta p_{k r}}{G_{0} \varepsilon_{0}^{2} \psi} .
$$

The loss factor (energy absorption coefficient) $\Psi$ is the ratio of the energy irreversibly absorbed by the body during one deformation cycle to the body's potential energy corresponding to the deformation amplitude during the same cycle. This value is determined for each brand of rubber and is tabulated along with other physical and mechanical properties of elastomeric materials. 


\section{Results and discussion}

\subsection{Fatigue lifetime calculation based on experimental data}

To illustrate based on the experimental data method for determining the fatigue durability with accordance to equations (1) and (2), plots of dependence of cycle numbers on the specific energy till $50 \mathrm{kNm} \cdot \mathrm{m}^{-3}$ for several rubber brands are presented in Fig. 1 for the working temperature $+25^{\circ} \mathrm{C}$. If the environment temperature changes, the number of cycles before failure is also changed.

Plots of dependence of cycle numbers on the working temperature for specific potential energy $15 \mathrm{kNm} \cdot \mathrm{m}^{-3}$ are shown in Fig. 2. Such diagrams are visual and convenient for preliminary selection of a rubber grade for a given number of cycles.

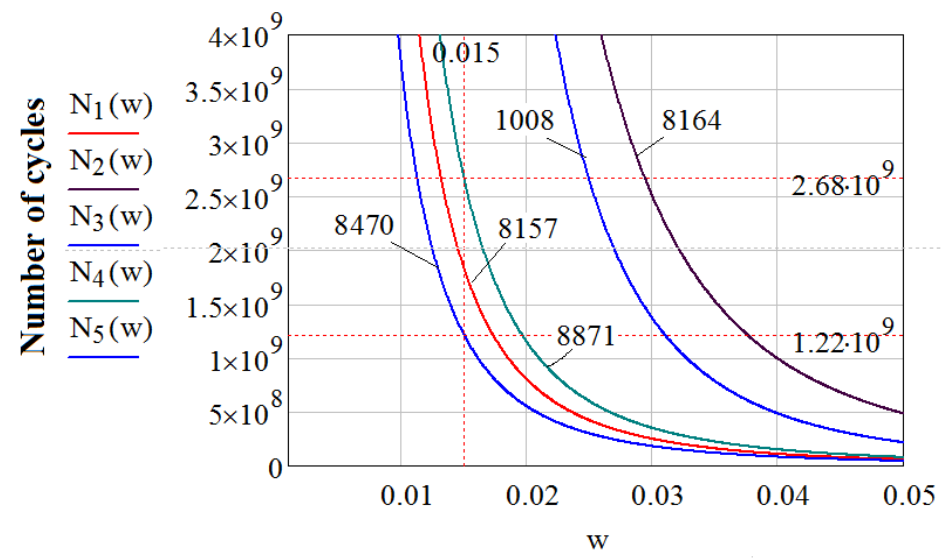

Specific potential energy, MPa

Fig. 1. Plot of dependence of number of cycles on specific potential energy of vibro-absorber under working temperature $25^{\circ} \mathrm{C}$
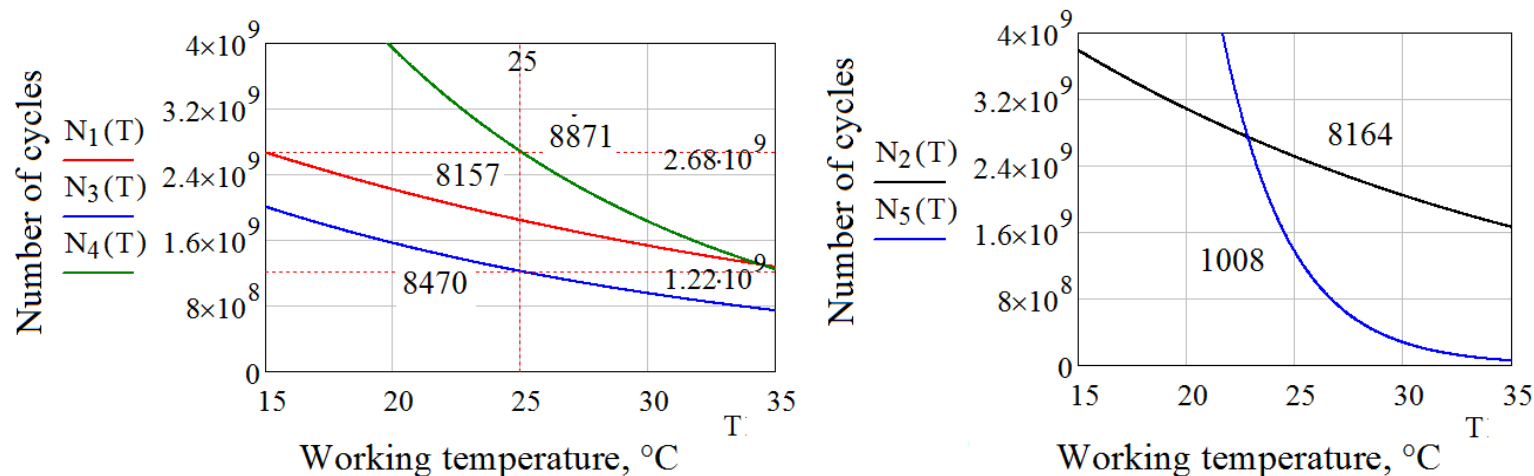

Fig. 2. Plot of dependence of cycle number of vibro-absorber on working temperature for specific potential energy $W=0.015 \mathrm{MJ} \cdot \mathrm{m}^{-3}$

\subsection{Dissipative damage criterion for lifetime evaluation}

The examples of application of the method, based on this criterion, are given below. The considered anti - vibration damper is a rubber - metal block (BRM), consisting of rubber solid in the form of a rectangular prism and connected with two metal plates. The drawing of the block is shown in Fig. 3, the dimensions of the considered blocks BRM102 and BRM103 are given in Table 2. Rubber brand 511562 is applied for block fabrication. Such rubber-metal blocks are used as the main elastic link in vibrating conveyors, screening conveyors, vibrating mills, vibrating feeders and so on. These blocks can take periodic load with a frequency up to $500 \mathrm{~Hz}$.

Uniaxial compression in the normal to metal plate direction is considered; the relative strain does not exceed $20 \%$, i.e. the stress = strain relationship remains linear. In order to calculate the number of cycles in accordance with equation (18), it is necessary to calculate the selfheating temperature of the element under the action of a cyclic compressive load. For this purpose, the heat balance equation may 
be simplified for the case of vibration motion, as it is shown in [10], and may be solved approximately, assuming that almost $80-90 \%$ of the dissipated energy is converted into heat.
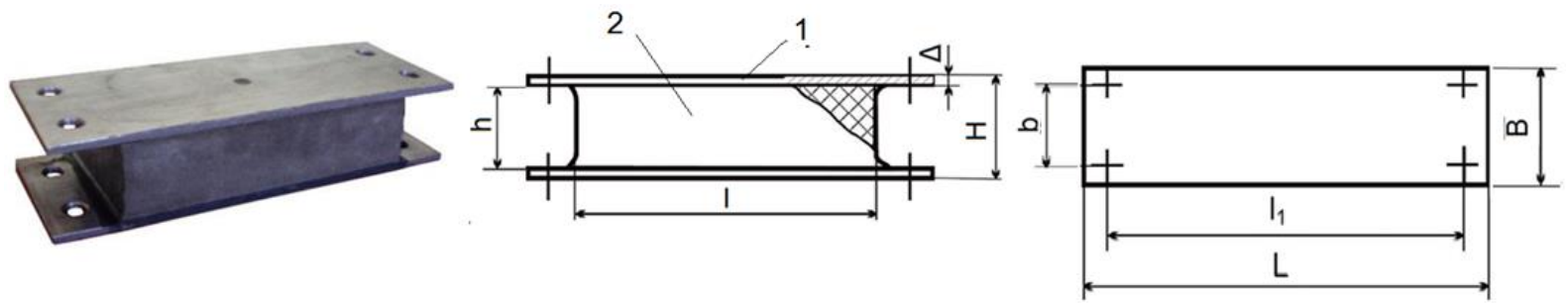

Fig. 3. Testing sample of BRM rubber vibro-absorber:

1 - metal plate; 2 - rubber prism

Table 2

Dimensions of testing vibro-absorbers

\begin{tabular}{|l|c|c|c|c|c|c|c|c|}
\hline & $\mathbf{L}, \mathbf{m}$ & $\mathbf{B}, \mathbf{m}$ & $\mathbf{H}, \mathbf{m}$ & $\mathbf{l}, \mathbf{m}$ & $\mathbf{l}_{\mathbf{1}} \mathbf{m}$ & $\mathbf{b}, \mathbf{m}$ & $\mathbf{h}, \mathbf{m}$ & $\Delta, \mathbf{m}$ \\
\hline BRM102 & 0.28 & 0.10 & 0.06 & 0.20 & 0.24 & 0.05 & 0.05 & 0.005 \\
\hline BRM103 & 0.40 & 0.10. & 0.06 & 0.32 & 0.36 & 0.05 & 0.05 & 0.005 \\
\hline BRM104 & 0.48 & 0.12 & 0.06 & 0.40 & 0.44 & 0.05 & 0.05 & 0.005 \\
\hline
\end{tabular}

The energy dissipation function in unit volume per unit time irreversibly transforming into heat may be calculated as average energy over the entire volume:

$$
W_{a v}=\frac{\omega}{2 \pi} \psi \frac{P \Delta_{0}}{2 V}=n \psi \frac{\varepsilon_{0}^{2} G_{0} k s t}{2},
$$

where $W_{a v}-$ energy dissipation function, $\mathrm{W} \cdot \mathrm{m}^{-3}$

$\omega$ - angular velocity, $\mathrm{s}^{-1} \cdot n=\omega / 2 \pi, \mathrm{Hz}$

$P$ - amplitude of the compression force, $\mathrm{N}$;

$\Delta_{0}$ - initial compressive deformation, $\mathrm{m}$;

$\varepsilon_{0}$ - initial relative compressive deformation;

$V$-rubber element volume, $V=B l h, \mathrm{~m}^{3}$.

$k s t$ - stiffness factor of the rubber block depending on its dimensions.

Taking into account that heat removal through free side surfaces of the BRM block is insignificant in comparison with heat removal through metal surfaces due to the small heat transfer coefficient at the rubber - air interface, it may be neglected. Assuming that $80 \%$ of the dissipated energy transfers into heat, and also assuming that in the initial state the temperature inside the entire element is the same, self - heating temperature is the same during operation, we can obtain the following expression for determining the maximal temperature inside the element in its center:

$$
\Theta_{\max }=\frac{W_{a v} 0.8}{\lambda} \frac{h^{2}}{3}\left(\frac{1}{4}+\frac{1}{h H_{2}}\right),
$$

where $\Theta_{\max }-$ maximal self-heating temperature, ${ }^{\circ} \mathrm{C}$;

$\lambda$ - coefficient of thermal conductivity, $\mathrm{W} \cdot \mathrm{m}^{-1} \cdot \mathrm{deg}^{-1}$;

$\mathrm{H}_{2}$ - heat transfer coefficients at the rubber-metal interface, $\mathrm{m}^{-1}$.

Substituting formulas (19) and (20) into equation (18), we obtain the cycle number dependence on the relative deformation during compression (until the local destruction):

$$
N^{*}\left(\varepsilon_{0}\right)=\frac{2 k_{1}\left(273+\Theta_{\max }\left(\varepsilon_{0}\right)\right) \Delta p_{k r}}{G_{0} \varepsilon_{0}^{2} \psi} .
$$

For BRM103 the parameter values in this equation are as follows: instant shear modulus $G_{0}=0.85 \mathrm{~Pa}$, loss factor $\psi=0.16, k_{1}=2.7 \cdot 10^{-16} \mathrm{~N} \cdot \mathrm{m} \cdot \mathrm{K}^{-1}, \Delta p_{k r}=3.64 \cdot 10^{25} \mathrm{~m}^{-3}, \lambda=0.293 \mathrm{~W} \cdot \mathrm{m}^{-1} \cdot \mathrm{deg}^{-1}$, 
$H_{2}=5240 \mathrm{~m}^{-1}, k s t=6.6$. Plots of dependence of the maximal self-heating temperature and the number of working cycles on relative deformation for frequencies 5, 25, 50 and $100 \mathrm{~Hz}$ are presented in Fig. 4.
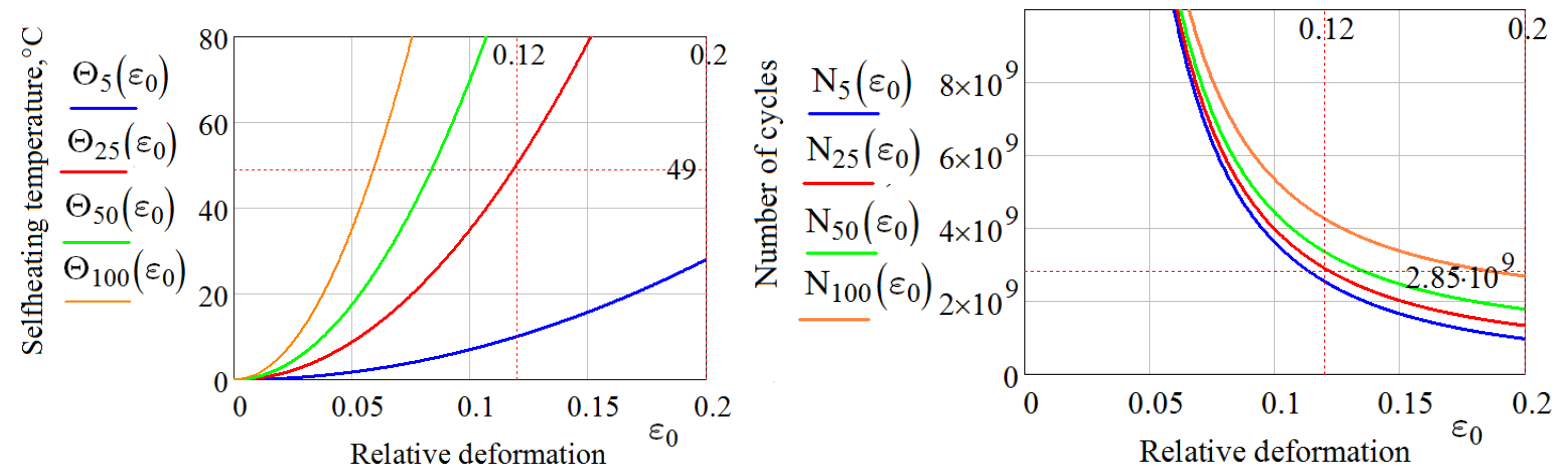

Fig. 4. Plots of dependence of maximal temperature and cycle numbers on relative deformation for frequencies $5,25,50$ and $100 \mathrm{~Hz}$

It was experimentally established for a batch of BRM103 blocks, working under compression with frequency $25 \mathrm{~Hz}$ and $\varepsilon_{0}=0.12$, that the limiting cycle number is $2.3 \cdot 10^{9}$. The analytical result for this condition is $2.85 \cdot 10^{9}$ cycles (see Fig. 4), the difference is $24 \%$; the received analytical results may be considered as satisfactory. The difference may be explained by the fact that heating of rubber during operation leads to a change in the mechanical properties of the elastomeric material - the deformation modulus $G_{0}$ and the absorption coefficient $\psi: G_{0}$ may increase by $25 \%$ and $\psi$ may decrease by $20 \%$ [17 - 19]. These changes have not a large effect on the durability, but they influence the working efficiency of elastomers, that is, their damping ability. In the above example the changed characteristics are taken for calculation. Initial characteristics for rubber 51-1562 without fillers are $G_{0}=0.7 \mathrm{MPa}$ and $\psi=0.17$; the maximal self-heating temperature should not exceed $80=90{ }^{\circ} \mathrm{C}$; the total operating time should not exceed 27000 - 30000 hours, since approximately after this limit destruction of rubber 51-1562 begins [19]. Working time for the analytically received number of cycles is 31600 hours; the experimental working time is 25600 hours, for this time $G_{0}=0.84 \mathrm{MPa}$ and $\psi=0.14$ [19].

In the next example we consider three elements BRM102, BRM103 and BRM104 working under compression with the frequency $25 \mathrm{~Hz}$. The difference will be only in the stiffness factor of blocks, which is equal 6.1, 6.6 and 7.6, respectively. In Fig. 5 plots of dependence of the cycle numbers on relative deformation for elements BRM102, BRM103 and BRM104 are shown; for these blocks the same relative deformation is caused by different forces.
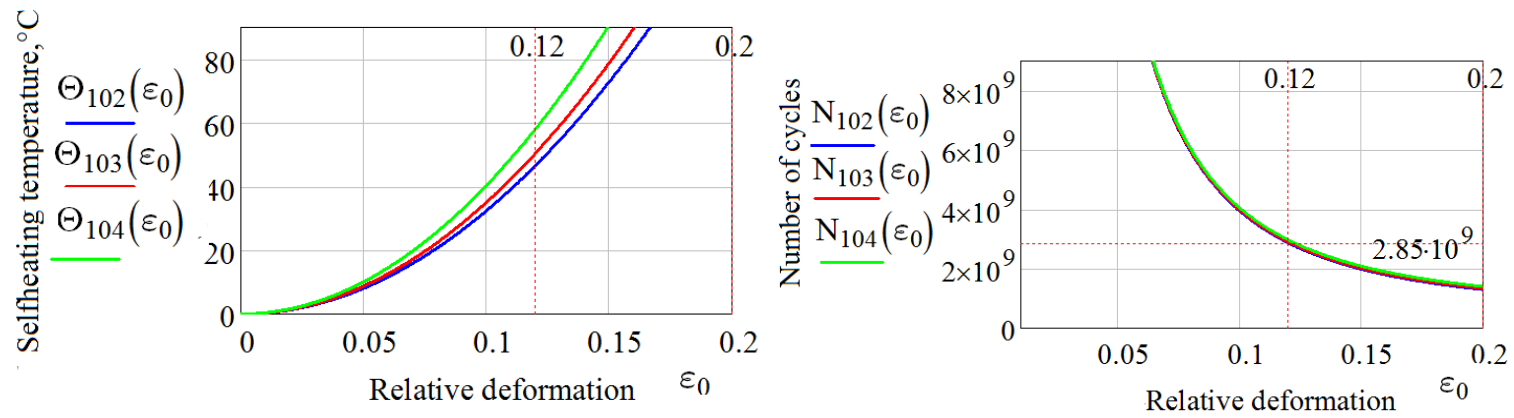

Fig. 5. Plots of dependence of maximal temperature and cycle numbers on relative deformation for BRM102, BRM103 and BRM104 for frequency $25 \mathrm{~Hz}$

It is seen from the equation (19) that the dissipation energy linearly depends on the vibration frequency, the maximal temperature linearly depends on the dissipation energy, and the cycle numbers linearly depend on the maximal temperature, hence, the number of cycles linearly depends on the vibration frequency. This fact was experimentally shown in [20] without a theoretical background.

Using the same approach, the operation of the BRM block under uniaxial shear may be estimated. 


\section{Conclusions}

1. The work presents two approaches to determining the rubber durability - experimental and analytical. The analytical method, based on dissipative damage criteria, is very convenient for presetting the size of the elastomeric element for an anti-vibration device; it allows to check all aspects of element's operation. It is shown on the example of uniaxial cyclic compression of a rubber prism.

2. The lifetime of the vibro-isolation rubber element depends not only on the elastomeric material properties, but also on the loading conditions and on the form and construction of the anti-vibration device.

3. Work under cyclic loading causes heat generation in rubber and changing of its physical and mechanical properties: the modulus of elasticity increases, the absorption coefficient decreases.

4. Frequency of deformation linearly influences the cycle numbers: they increase with increasing the frequency, but the total operation time should not exceed a certain value.

5. The fatigue life estimation procedure, based on the dissipative damage criterion proposed in this work, may be successfully used for the fatigue design of rubber components at the early design stage.

\section{References}

[1] Потураев В.Н., Дырда В.И., Резиновые детали машин (Rubber Machine Elements). Moscow: Mashinostrojenie, 1977. 217 p. (In Russian).

[2] Gent A.N., Mars W. Strength of elastomers. Science and technology of rubber, 2013. pp. 419-454.

[3] Brinson H.F., Brinson L.C. Polymer engineering science and viscoelasticity. An introduction. Second edition. Springer, 2015. 482 p.

[4] Bauman J. T. Fatigue, Stress and Strain of Rubber Components: Guide for Design Engineers. Carl Hanser Verlag, Munich, 2008. 214 p.

[5] Lake G.J. Fatigue and Fracture of Elastomers, Rubber Chem. \& Technology, vol. 68, 1995, pp. 435-460.

[6] Huneau B., Masquelier I., Le Saux V. etc. Prediction of fatigue properties of natural rubber based on the descriptions of the cracks population and of the dissipated energy. Polymer Testing, Volume 59, May 2017, Pages 67-74.

[7] Dyrda V.I., Sokol S.P., Tverdohleb T.Ye., etc. Forecasting of durability of rubber parts by means of applied fracture criteria. Геотехнічна механіка. 2013.108, pp.155-163 (in Russian). http://dspace.nbuv.gov.ua/bitstream/handle/123456789/59587/13-Dyrda.pdf?sequence $=1$

[8] Marco Y., Huneau B., Masquelier I. etc. Prediction of the fatigue properties of natural rubber based on the descriptions of the cracks population and of the dissipated energy. Polymer Testing, Elsevier, 2017, 59, pp. 67-74.

[9] Mars W.V. Fatigue life prediction for elastomeric structures. Rubber Chemistry and Technology 80, 2007, no. 3: pp. 481-503.

[10] Ляпунов В.Т., Лавендел Э.Э., Шляпочников С.А. Резиновые виброизоляторы, справочник. (Rubber vibration isolators, handbook). Leningrad: Sudostrojenie, 1988. 216 p. (In Russian).

[11] Rausch S., Ruderer M.A., Enkle W. etc. Lifetime prediction of elastomer components within gasoline engines. Proceeding of the 9th European Conference on Constitutive Models for Rubbers (ECFCMR IX), pp. 363-366.

[12] Saintier N., Cailletaud G., Piques R. Multiaxial fatigue life prediction for a natural rubber. International Journal of Fatigue, Elsevier, 2006, 28 (5-6), pp.530-539.

[13] Ayouba G., Naït-abdelaziza M., Zaïria F. ets. Multiaxial fatigue life prediction of rubber-like materials using the continuum damage mechanics approach. Procedia Engineering 2 (2010) pp. 985-993. Fatigue 2010 Published by Elsevier.

[14] Woo C.S., Kim W.D. Fatigue lifetime prediction methodology of rubber components. High Performance Structures and Materials IV. pp. 285 - 293,. WIT Transactions on The Built Environment, Vol 97, 2008, WIT Press. [online] [21.03.2021] Available at: https://www.witpress.com. $\mathrm{s}^{-1}$ ecure/elibrary/papers/HPSM08/HPSM08030FU1.pdf

[15] Chung J. and Kim N.H. Numerical methods of multiaxial fatigue life prediction for elastomers under variable amplitude loadings. Wiley Publishing Ltd. Fatigue and Fracture of Engineering 
Materials and Structures, 2016, 39, pp. 866-876 [online] [21.03.2021] Available at: https://mae.ufl.edu/nkim/Papers/paper76.pdf

[16] Chieh C. W., Aidy Ali, Sanuddin A. etc. Durability Simulation of Elastomeric Materials Using Finite Element Method (Fem). Pertanika J. Sci. \& Technol. 18 (2): (2010) pp. 441-450. https://www.academia.edu/2829362/Durability_Simulation_of_Elastomeric_Materials_Using_Fin ite_Element_Method_FEM_

[17] Gröhlich M., Böswald M., Winter R. Vibration damping capabilities of treatments with frequency and temperature dependent viscoelastic material properties. Proceedings of ICA 2019 - 23rd International Congress on Acoustics, September 9-13, 2019, Aachen, Germany, pp. 4273-4280.

[18] Schieppati J., Schrittesser B., Wondracek A. etc. Heat build-up of rubbers during cyclic loading. Proceeding of 2019 European Conference on Constitutive Models for Rubber - ECCMR 2019 Available at: http://eccmr.org/wpcontent/uploads/2019/06/Full_paper_Jacopo_Schieppati.pdf

[19]Дырда В.И., Гребенюк С.Н., Сокол С.П. еtc./ Некоторые Проблемы Исследований Нелинейных Эффектов в Эластомерах при Длительном Циклическом Разрушении.(Some Problems of Investigation of Nonlinear Effects in Elastomers with Long Cyclic Destruction). Геотехнічна механіка. 2019. № 144, pp. 77-88, (In Russian). [online] [21.03.2021] Available at: http://geotm.dp.ua/attachments/article/4011/9.pdf

[20] Mohammed A., Nemat-Alla M.M., Emara K.M. Effect of Frequency on Fatigue Lifetime of SBR and NBR Compounds. International Journal of Scientific \& Engineering Research, Volume 5, Issue 1, 2014, pp. 865-870. [online] [21.03.2021] Available at: https://www.ijser.org/paper/Effect-ofFrequency-on-Fatigue-Lifetime-of-SBR-and-NBR-Compounds.html 